\title{
Bebida à base de flocos de abóbora com inulina: características prebióticas e aceitabilidade
}

\author{
Drink based on pumpkin flakes containing insulin: \\ prebiotic characteristics and acceptability
}

Karina Correia da SILVEIRA ${ }^{1}$

Jacira Antonia BRASIL²

Alda Verônica de Souza LIVERA ${ }^{3}$

Silvana Magalhães SALGADO 3

Zelyta Pinheiro de FARO'

Nonete Barbosa GUERRA ${ }^{3}$

RE S U M O

\section{Objetivo}

Formular bebida para crianças de 4 a 6 anos, à base de flocos de abóbora adicionada de inulina, e caracterizá-la quanto ao valor nutricional, à aceitação e ao efeito prebiótico.

\section{Métodos}

O valor nutricional da bebida foi avaliado por meio de análise da umidade, de proteínas, lipídeos, cinzas, fibra alimentar, carboidratos e carotenóides. As características microbiológicas foram avaliadas por meio de análises de coliformes a $35^{\circ} \mathrm{C}$ e a $45^{\circ} \mathrm{C}$, Staphylococcus aureus, Salmonella ssp, Bacillus cereus, de contagem padrão de aeróbios, bolores e leveduras. A aceitabilidade foi determinada por testes sensoriais, aplicados em duas creches da região metropolitana do Recife (PE), o efeito prebiótico foi avaliado por fermentação in vitro, em meio diferencial para bactérias homefermentativas e heterofermentativas-Ágar, e as análises de ácidos graxos de cadeia curta, foram avaliadas por cromatografia a gás.

\section{Resultados}

Os resultados físico-químicos demonstram que as formulações pouco diferiram quanto à composição centesimal e que a ingestão 200mL/dia contribui, em média, com 10,8\%, 36,0\%, 10,2\%, 12,6\%, 37,1\% e 126,4\% da Recomendação de Ingestão Diária de energia, proteínas, carboidratos, lipídeos, fibra alimentar e carotenóides, respectivamente. Os resultados microbiológicos comprovaram a inocuidade do produto; os sensoriais que as formulações obtiveram uma aceitação em torno de $70 \%$ e os dados da avaliação do efeito prebiótico sugerem maior estudo sobre o tema.

\footnotetext{
${ }^{1}$ Universidade Federal de Pernambuco, Departamento de Nutrição. Av. Prof. Moraes Rego, 1235, Cidade Universitária, 50670-901, Recife, PE, Brasil. Correspondência para/Correspondence to: K.C. SILVEIRA. E-mail: <kcsilveira@hotmail.com>. ${ }^{2}$ Universidade Federal Rural de Pernambuco, Departamento de Tecnologia Rural. Recife, PE, Brasil.

${ }^{3}$ Universidade Federal de Pernambuco, Departamento de Nutrição, Laboratório de Experimentação e Análise de Alimentos. Recife, PE, Brasil.
} 


\section{Conclusão}

Os resultados permitem concluir que as formulações são nutricionalmente adequadas para pequenas refeições de crianças de 4 a 6 anos, pois, além de prevenir a carência de vitamina A apresentam indícios de efeitos prebióticos.

Termos de indexação: Abóboras. Vitamina A. Inulina. Valor nutricional.

\section{A B S T R A C T}

\section{Objective}

The objective of this study was to formulate a drink for kids aging from 4 to 6 years based on pumpkin seeds and with insulin, and characterize the drink regarding its nutritional value, acceptance and prebiotic effect.

\section{Methods}

The nutritional value of the drink was assessed by determining moisture, proteins, lipids, ash, dietary fiber, carbohydrates and carotenoids. The microbiological characteristics were assessed by coliform analysis at $35^{\circ} \mathrm{C}$ and $45^{\circ} \mathrm{C}$, Staphylococcus aureus, Salmonella ssp, Bacillus cereus, standard aerobic organism count, yeasts and molds. Acceptance was determined by sensory tests in two daycare units of the metropolitan region of Recife (PE). The prebiotic effect was assessed by in vitro fermentation in a differential medium for homofermentative and heterofermentative bacteria. Short chain fatty acids were determined by gas chromatography.

\section{Results}

The physical-chemical results showed that the formulations differed slightly regarding the centesimal composition and that the ingestion of $200 \mathrm{~mL} /$ day contributes, on average, with $10.8 \%, 36.0 \%, 10.2 \%$, $12.6 \%, 37.1 \%$ and $126.4 \%$ of the recommended daily intake of energy, proteins, carbohydrates, lipids, dietary fiber and carotenoids respectively. The microbiological results proved that the product is innocuous. The acceptance of the product was of roughly $70 \%$. The results of the prebiotic effects showed that more research is necessary.

\section{Conclusion}

The results allow us to conclude that the formulations are nutritionally adequate for small meals of children aging from 4 to 6 years, since the product not only avoids vitamin A deficiency but also presents evidence of some prebiotic effects.

Indexing terms: Cucurbitas. Vitamin A. Inulin. Nutrition value.

\section{N T R O D U Ç Ã O}

Um dos grandes problemas de Saúde Pública nos países em desenvolvimento é a carência de vitamina $A$, nos aspectos dietético, bioquímico ou clínico, com repercussões sistêmicas que afetam as estruturas epiteliais de diferentes órgãos, sendo os olhos os mais atingidos. No Brasil, desde 1994, o Ministério da Saúde vem intervindo para a eliminação desta deficiência. Entre as ações se destacam a suplementação com megadoses desta vitamina a crianças de 6 a 59 meses de idade, residentes em áreas consideradas de risco; as ações educativas implementadas pelos agentes comunitários de saúde e pelos meios de comunicação, tornando disponíveis informações que visem à seleção de alimentos ricos em retinol e carotenóides.

A abóbora, conhecida no Nordeste do Brasil como jerimum, é bastante consumida nesta região, sétima na lista de vegetais mais consumidos, e ocupa o quinto lugar em volume de comercialização no Estado de Pernambuco'. Em 2004, Seo et al. ${ }^{2}$ confirmaram que a espécie $C$. moschata apresenta mais de $80 \%$ de sua composição de carotenóides da fração $\beta$-caroteno além de $\alpha$-caroteno, lutéina, licopeno, criptoxantina e cis $\beta$-caroteno, precursoras de provitamina $A$. 
Pesquisadores têm se empenhado no desenvolvimento de vários produtos, entre estes os flocos de abóbora e a bebida produzida a partir deles. Os flocos são obtidos por processo de desidratação, que é econômico e simples. Este processo permite ainda a redução do peso e do volume do produto inicial, o que facilita a embalagem, o transporte e o armazenamento do produto final, podendo apresentar estabilidade microbiológica por um período mínimo de 180 dias, desde que devidamente manipulado ${ }^{1,3}$.

Outro aspecto observado diz respeito à Ciência dos Alimentos, que tem tomado um novo rumo com a contextualização dos alimentos funcionais, ganhando uma dimensão extra no século XXI. A constatação da relação inversamente proporcional entre o aumento do consumo de frutas e hortaliças e a redução do risco de cardiopatias e de certos tipos de câncer (colón, mama e próstata) levou ao crescente interesse dos consumidores por esses alimentos, servindo de elemento propulsor para pesquisas sobre o assunto, que identifiquem os compostos naturais com propriedades funcionais ${ }^{4}$. Entre esses compostos destacamse os frutooligossacarídeos (FOS), em especial a inulina, que estimula o crescimento das bactérias benéficas no cólon, as quais, por sua vez, suprimem a atividade de outras bactérias putrefativas como: Escherichia coli, Streptococos faecales, Proteus e outras.

Frente aos atuais fatores de conversão de carotenóides em retinol5; ao baixo custo dos flocos desidratados de abóbora e à capacidade dos flocos em aumentar a reserva hepática de vitamina $A^{3,6}$, foi proposto adicionar à bebida, a inulina. Isso porque, por ser considerada um modificador reológico, sua adição a esse produto pode contribuir para a melhoria da qualidade sensorial do mesmo, modificando a textura, além de conferir, efeitos prebióticos, que potencializariam a bebida, que poderia ser uma alternativa para a prevenção e o controle da carência da vitamina $A^{3,6}$.

\section{MÉ T O D O S}

O estudo teve como padrão a bebida desenvolvida por Faro ${ }^{3}$, que consiste na formu- lação A: 6,0\% de flocos de abóbora, 12,0\% de leite em pó integral, 3,0\% de açúcar refinado e $79,0 \%$ de água. As formulações experimentais foram: formulação B (6,0\% de flocos de abóbora, $12,0 \%$ de leite em pó integral, 3,0\% de açúcar refinado, $0,5 \%$ de inulina e $78,5 \%$ de água) e a formulação C (6,0\% de flocos de abóbora, 12,0\% de leite em pó integral, 3,0\% de açúcar refinado, $1,0 \%$ de inulina e $78,0 \%$ de água).

A abóbora (C. moschata variedade moranga) para a fabricação dos flocos foi adquirida na Companhia de Abastecimento e de Armazéns Gerais de Pernambuco (CEAGEPE), o leite em pó integral e o açúcar refinado foram obtidos no comércio local e a inulina (Oraft-Raftiline HPX, BENEO) foi doada pela empresa Orafti-Active Food Ingredients - Bélgica.

Os flocos desidratados de abóbora para a elaboração do pó para bebida foram obtidos por processo de secagem em tambor, utilizando a metodologia descrita por Faro 3 .

Com o objetivo de verificar a inocuidade da bebida foram realizadas, conforme a resolução da diretoria colegiada (RDC) n¹2/20017 , análises de Bacillus cereus (método 980.31), de coliformes a $35^{\circ} \mathrm{C}$ (método 991.14 ), de coliformes a $45^{\circ} \mathrm{C}$ (método 986.33), de Salmonella spp (métodos 996.08 e 967.26), segundo a Association of Official Analytical Chemistry (AOAC) ${ }^{8}$, e de Staphylococcus aureus (método 2003.08), segundo a $\mathrm{AOAC}^{9}$. Também foram realizadas análises de contagem padrão de aeróbios (método 990.12), bolores e leveduras (método 997.02), segundo a $\mathrm{AOAC}^{8}$.

A composição química do produto foi determinada conforme a $\mathrm{AOAC}^{8}$, verificando a umidade (método 935.29), o resíduo mineral fixo - cinzas (método 930.22-32.3.08), os lipídeos (método 963.15-31.4.02), as proteínas (método 991.20-33.2.11) e a fibra alimentar (método 985.29-45.4.08). Os carboidratos totais foram obtidos por diferença, os valores de carotenóides foram determinados segundo Rodriguez-Amaya et al. ${ }^{10}$ e o teor de vitamina $A$ presente nas formulações provenientes dos flocos de abóbora, 
foi estimado utilizando os valores de carotenóides totais. Como sugere a literatura, foi considerado que em torno de $80 \%$ dos carotenóides presentes na abóbora são constituídos de $\beta$-caroteno, a conversão de $\beta$-caroteno em retinol (1:12) 2,5,11.

A realização da análise sensorial de um produto, particularmente antes de seu lançamento no mercado, é uma etapa vital do processo, pois pode evitar problemas futuros em termos de aceitação. Para avaliar a aceitação da bebida, devido à faixa etária das crianças, foi utilizado o Índice de Aceitabilidade Proporcional, que é um tipo de teste de aceitabilidade, utilizado em testes afetivos. Esses testes foram realizados mediante aprovação do Comitê de Ética em Pesquisa envolvendo seres humanos, do Centro de Ciências da Saúde da Universidade Federal de Pernambuco (protocolo de pesquisa $n^{\circ}$ 244/2005-CEP/CCS). 0 trabalho recebeu autorização da direção das creches, da Secretaria de Educação, Esporte e Lazer do Município do Recife e dos pais/responsáveis das crianças que participaram dos painéis sensoriais.

As formulações $A, B, C$ foram reconstituídas no local do teste utilizando água e equipamentos pertencentes às instituições. Foram realizados nove ensaios em cada creche, três ensaios para cada formulação, sendo a ordem de apresentação das formulações às crianças obtida por sorteio.

A aceitação do produto foi mensurada conforme o Índice de Aceitabilidade Proporcional ${ }^{12}$. O Índice de Aceitabilidade Proporcional foi calculado de acordo com a quantidade do produto distribuído a cada provador ${ }^{12}$. A análise sensorial consistiu em um painel composto por 49 crianças em idade pré-escolar (4 a 6 anos), de ambos os sexos, de duas creches, uma beneficente e outra governamental, da Cidade do Recife/ Pernambuco. Foram servidos $50 \mathrm{~mL}$ da formulação em copos identificados com os nomes das crianças, no horário do lanche matinal (9h), depois o consumo foi quantificado utilizando uma proveta.

O delineamento estatístico da análise sensorial foi feito por um experimento completo em blocos ao acaso, avaliados por Análise de
Variância - ANOVA $(p<0,05)$, utilizando o programa Minitab versão11.

Para avaliar o efeito prebiótico foi realizada a fermentação das três formulações segundo a metodologia proposta por Barry et al. ${ }^{13} \mathrm{e}$ Cambrodón \& Martín-Carrón ${ }^{14}$. No processo de fermentação, as amostras pesando $100 \mathrm{mg}$ foram colocadas em tubos de ensaio com $8 \mathrm{~mL}$ do meio de fermentação ${ }^{13}$, incubadas a $37^{\circ} \mathrm{C}$, em jarra de Gaspak com sistema anaeróbico, durante 12 horas. Posteriormente, a cada tubo de ensaio foram adicionados $2 \mathrm{~mL}$ do inóculo, preparado a partir de fezes de lactentes suspensas no meio de fermentação, elaborado segundo Barry et al. ${ }^{13}$, na proporção de $10 \mathrm{~mL} / \mathrm{g}$ de fezes, incubadas a $37^{\circ} \mathrm{C}$, sob anaerobiose durante 12 horas. Os tubos foram mantidos em sistema anaeróbico, em banho-maria com agitação e temperatura controlada a $37^{\circ} \mathrm{C}$, permanecendo nessas condições durante o período de fermentação. A cada intervalo de $2 \mathrm{~h}$, uma alíquota de $1 \mathrm{~mL}$ do líquido metabólico foi utilizada para contagem de bactérias homofermentativas e heterofermentativas, e o restante foi utilizado para análise de ácidos graxos de cadeia curta (AGCC).

Para quantificar e identificar as bactérias homofermentativas e heterofermentativas utilizouse o meio diferencial HHD agar ${ }^{15}$. Na contagem de bactérias homofermentativas e heterofermentativas, as amostras dos líquidos metabólicos foram incubadas por plaqueamento em superfície, e as condições de incubação utilizadas foram 37 , com variação de $1^{\circ} \mathrm{C}$ por $72 \mathrm{~h}$ em sistema anaeróbico com sistema gerador de anaerobiose.

As análises de ACGC (acético, propriônico e butírico) foram realizadas em cromatográfico a gás (CG Máster), equipado com um detector de ionização de chama e coluna capilar de $0,53 \mathrm{~mm}$ x 30m x $1 \mu \mathrm{m}$ de PolietilenoGlicol (Carbowax 20M) e utilizando hidrogênio como gás transportador a $5 \mathrm{~mL} /$ minuto $^{16}$.

\section{RES ULTA D OS E DISCUSS Ã O}

Os resultados dos ensaios microbiológicos para coliformes a $35^{\circ} \mathrm{C} / \mathrm{g}(\mathrm{mL})$, coliformes a 
$45^{\circ} \mathrm{C} / \mathrm{g}(\mathrm{mL})$, Staphylococcus aureus, Salmonella spp e Bacillus cereus apresentaram conformidade com a legislação vigente ${ }^{7}$. As análises de bolores e leveduras, bem como a contagem padrão de aeróbios, embora não exigidas pela legislação, foram efetuadas para avaliar a qualidade higiênico-sanitária das formulações, seus resultados indicam, de forma geral, as boas condições higiênicas no processamento ${ }^{7,17}$.

A composição química das formulações descritas na Tabela 1 demonstra que as bebidas pouco diferem nos parâmetros analisados. $O$ aumento da umidade na formulação $C$ em relação às demais pode ser atribuído ao maior percentual de inulina, considerada uma substância higroscópica. Quanto ao teor de fibras alimentares, apesar de não ter sido dosada a inulina, verificase que a adição da mesma resultou em um aumento deste parâmetro. Na Tabela também se encontram representados os valores de carotenóides totais, a estimativa de $\beta$-caroteno, de vitamina $A$ (por grama da bebida e por ingestão de $200 \mathrm{~mL}$ da bebida).

Ressalta-se que além do seu efeito prebiótico a presença de inulina pode aumentar a biodisponibilidade de minerais (cálcio e magnésio) importantes no crescimento e desenvolvimento infantil ${ }^{18,19}$. Também se destaca o considerável teor de proteínas de alto valor biológico das formulações provenientes do leite.

Tabela 1. Composição química das formulações da bebida à base de flocos de abóbora com inulina. Recife (PE), 2006.

\begin{tabular}{lrrr}
\hline \multirow{2}{*}{ Componentes } & \multicolumn{3}{c}{ Formulação } \\
\cline { 2 - 4 } & \multicolumn{1}{c}{ A } & \multicolumn{1}{c}{ B } & \multicolumn{1}{c}{ C } \\
\hline Umidade $(\mathrm{g} / 100 \mathrm{~g})$ & 1,89 & 2,02 & 2,28 \\
Cinzas $(\mathrm{g} / 100 \mathrm{~g})$ & 2,10 & 2,06 & 2,07 \\
Proteína $(\mathrm{g} / 100 \mathrm{~g})$ & 6,90 & 6,70 & 6,90 \\
Lipídeos $(\mathrm{g} / 100 \mathrm{~g})$ & 6,50 & 5,70 & 5,90 \\
Carboidratos totais $(\mathrm{g} / 100 \mathrm{~g})$ & 21,10 & 22,90 & 22,80 \\
Fibra alimentar $(\mathrm{g} / 100 \mathrm{~g})$ & 3,40 & 3,60 & 4,10 \\
Valor energético total $(\mathrm{kcal})$ & 157,50 & 155,30 & 155,20 \\
Carotenóides totais $(\mu \mathrm{g} / \mathrm{g})$ & 91,98 & 94,82 & 97,68 \\
$\beta$-caroteno $(\mu \mathrm{g} / \mathrm{g})$ & 73,16 & 75,85 & 78,14 \\
Vitamina A $(\mu \mathrm{g} / \mathrm{g})$ & 6,13 & 6,32 & 6,51 \\
Vitamina A $(\mu \mathrm{g} / 200 \mathrm{~mL}$ bebida) & 257,54 & 271,80 & 286,53 \\
\hline
\end{tabular}

No que se refere ao teor de vitamina A, os valores determinados nas formulações superam a recomendação para esta vitamina, ratificando Faro $^{3}$ e Ambrósio et al. ${ }^{6}$, que demonstraram, respectivamente, a eficácia da bebida e dos flocos de abóbora na prevenção e no controle da carência da vitamina A na população infantil.

Baseados nos resultados da composição química das formulações e nas Recomendações Diárias de Ingestão para a faixa etária de 4 a 6 anos, com valor energético total (VET) de $1450 \mathrm{kcal},{ }^{20}$ os dados da Figura 1 demonstram a adequação da ingestão das três formulações de bebida e a Recomendação Diária de Ingestão (RDI). Considerando que as bebidas pouco diferem nos parâmetros químicos, em média a ingestão de $200 \mathrm{~mL} /$ dia da bebida contribuiria com 10,8\% da RDI de energia, $36,0 \%$ de proteína, $10,2 \%$ de carboidratos, $12,6 \%$ de lipídeos, $37,1 \%$ de fibra alimentar, ressaltando a contribuição de 126,4\% de vitamina A.

Uma vez que a ingestão diária é dividida em grandes refeições (desjejum, almoço e jantar) e pequenas refeições (denominadas de lanches), e que estas representam 5\%-10\% do VET, a ingestão de $200 \mathrm{~mL}$ ultrapassa as recomendações nutricionais preconizadas para a faixa etária de 4 a 6 anos $^{20}$. Tal fato poderia contribuir para melhorar o estado nutricional de crianças, uma vez que a formulação contém leite integral contribuindo com proteínas de alto valor biológico, conforme representado na Figura 2.

Quanto à aceitação do produto, a Tabela 2 expõe o resultado da média percentual de ingestão das formulações. Analisando a aceitação, verifica-se, a partir do teste $\mathrm{F}$-Snedecor, da ANOVA, que as formulações ( $A, B$ e $C$ ) não apresentam diferenças significantes ( $p$-valor $=0,463$ ), mas existe diferença entre a creche I e a creche II ( $p$-valor $<0,0001)$. Ou seja, as formulações, em média, têm a mesma aceitação nas creches, mas o comportamento da aceitação na creche I apresenta-se diferente da creche II. A aceitação das formulações na creche II foi superior à 


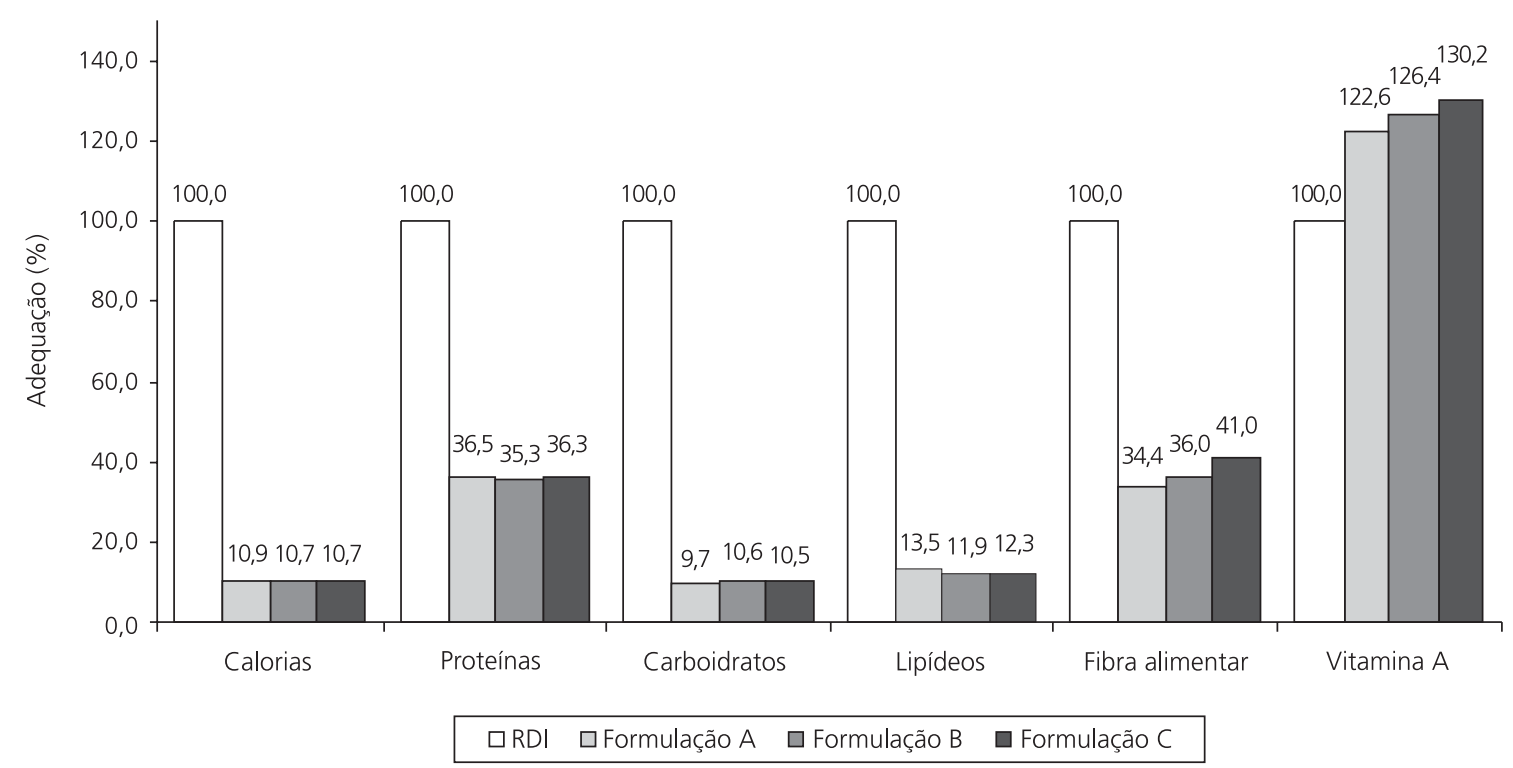

Figura 1. Adequação Nutricional das fórmulas da bebida à base de flocos de abóbora com inulina (200mL), de acordo com a recomendação diária de ingestão (RDI) para a faixa etária de 4 a 6 anos, baseado em 100\% do valor energético total de 1450kcal. Recife (PE), 2006.

Nota: RDI: recomendação diária de ingestão.

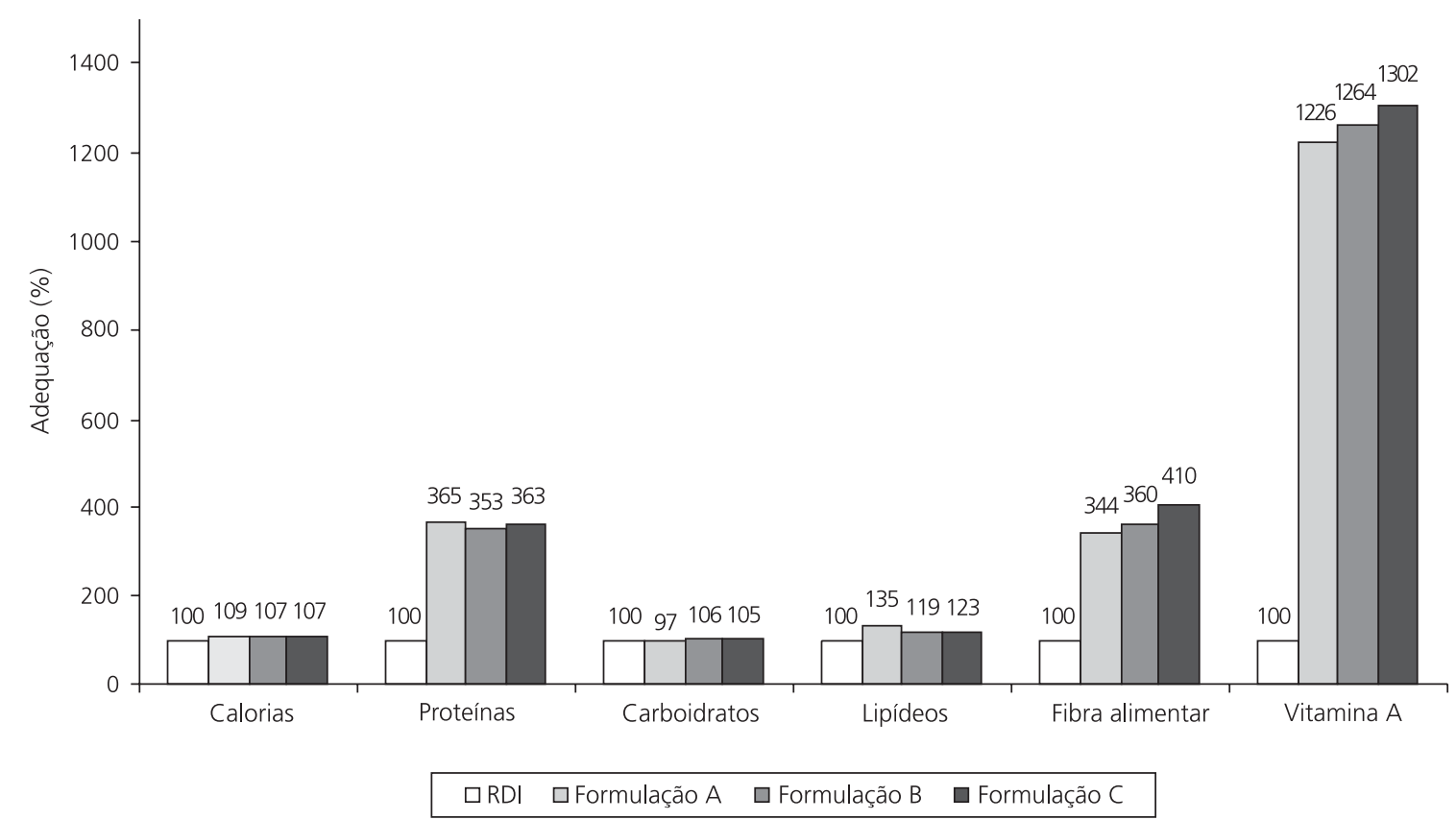

Figura 2. Adequação Nutricional das fórmulas da bebida à base de flocos de abóbora com inulina (200mL), de acordo com a recomendação diária de ingestão (RDI) para a faixa etária de 4 a 6 anos, baseada em 5-10\% do valor energético total de $1450 \mathrm{kcal}$. Recife (PE), 2006.

Nota: RDI: recomendação diária de ingestão. 
Tabela 2. Média do percentual de ingestão das formulações da bebida à base de flocos de abóbora com inulina. Recife (PE), 2006.

\begin{tabular}{lcccccccc}
\hline \multirow{2}{*}{ Formulação } & \multicolumn{3}{c}{ Creche I } & & \multicolumn{3}{c}{ Creche II } \\
\cline { 2 - 5 } \cline { 6 - 8 } & M & DP & CV\% & & M & DP & CV\% \\
\hline A & $60^{\mathbf{a}}$ & 49,28 & 81 & & $95^{\mathbf{b}}$ & 21,67 & 24 \\
B & $58^{\mathbf{a}}$ & 48,29 & 83 & & $87^{\mathbf{b}}$ & 27,66 & 32 \\
C & $62^{\mathbf{a}}$ & 46,28 & 76 & & $76^{\mathbf{b}}$ & 31,06 & 41 \\
\hline
\end{tabular}

M: Média de Ingestão; DP: desvio-padrão; CV: Coeficiente de Variação. Letras iguais valores não diferem estatisticamente entre si a um nível de significância de 5\%. Letras diferentes os valores diferem estatisticamente entre si a um nível de significância de 5\%.

aceitação na creche I. Estes resultados podem ser atribuídos às diferentes condições socioeconômicas das creches. Na creche II, o cardápio é menos diversificado e, assim, poderia contribuir para uma melhor aceitação de novos produtos.

Nos valores referentes à creche I observase que a aceitabilidade média da bebida foi de $60 \%$; desta forma, a bebida não se encontra dentro do valor aceitável ${ }^{12}$. Por outro lado, na creche Il o índice de aceitabilidade médio foi de $86 \%$.

De acordo com a Tabela 2, observa-se que a formulação $C$ apresenta um comportamento distinto entre as creches. Na creche I a formulação C obteve o maior resultado, enquanto na creche II a formulação obteve o menor. Analisando as possíveis causas, supõe-se que a ordem de apresentação das formulações tenha contribuído para esse comportamento; apesar de terem sido utilizados sorteios aleatórios houve coincidência na ordem de apresentação das formulações (ordem de apresentação na creche Il: formulação $C, B, C, C, B, B, A, A, A)$, sendo indicada a existência de uma relação inversa entre a ordem de apresentação e a preferência da formulação.

Estes resultados confirmam os estudos de Faro $^{3}$ no que se refere à aceitação de bebida à base de flocos de abóbora e os estudos de Hauly et al. ${ }^{21}$, segundo os quais a incorporação de inulina à bebida à base de soja não alterou a aceitação.

Quanto ao efeito prebiótico, após 12 horas de fermentação foi avaliado o líquido metabólico. Nas placas da contagem de bactérias homofermentativas e heterofermentativas foram encon- tradas colônias lisas com bordas completas, regulares, brilhantes, de consistência dura e coloração azul-esverdeada. Em meio HHD estas características são indicativas de colônias de bactérias homofermentativas ${ }^{15}$ e como representantes dessas bactérias há algumas espécies de lactobacilos, por exemplo, o L. acidophillus. Esses gêneros, juntamente com os Bifidobacterium, são considerados microrganismos probióticos 22,23 .

Por meio de coloração de Gram as colônias foram caracterizadas como bactérias Gram positivas, cocos ou bastões curtos de pequena curvatura. Estas características, segundo Boone ${ }^{24}$, sugerem que as bactérias encontradas fazem parte do gênero Lactobacillus.

Em meio HHD as bactérias heterofermentativas apresentam colônias brancas ${ }^{15}$, as bactérias Bifidobacterium bifidum, reconhecidamente heterofermentativas ${ }^{25}$, não foram encontradas nos ensaios efetuados. Esta ausência pode decorrer de uma possível competição entre os gêneros Lactobacillus e Bifidobacterium. Também tem sido referido que oligofrutose não influencia de forma significativa o desenvolvimento de culturas lácteas probióticas $^{26}$. Convém ainda lembrar que a presença de pectina (constituinte natural da abóbora) dificulta o aumento de bifidobactérias, por interferir na biodisponibilidade dos frutooli-gossacarídeos como substrato de fermentação ${ }^{27}$. Estes resultados sugerem a utilização de meios específicos para ambos os gêneros.

Ao analisar os dados da Tabela 3, foi observada uma variação na contagem bacteriana entre as formulações. As formulações B e C apresentaram maior estabilidade bacteriana. Esta dinâmica da população microbiana pode ser atribuída à concentração da inulina nas formulações ${ }^{27-30}$. Nesta última formulação a população bacteriana foi 10 vezes superior às outras duas formulações. Este resultado poder ser devido à contagem inicial da população bacteriana.

A diferença na concentração de inulina entre as três formulações, no entanto, não foi suficiente para determinar entre elas uma diferença significativa no crescimento bacteriano. Estes resul- 
Tabela 3. Contagem de bactérias homofermentativas nas formulações da bebida à base de flocos de abóbora com inulina, utilizando o meio de cultura HHD-Agar. Recife (PE), 2006.

\begin{tabular}{|c|c|c|c|}
\hline \multirow{2}{*}{ Horas } & \multicolumn{3}{|c|}{ Formulação } \\
\hline & $A$ & B & C \\
\hline 0 & $5,0 \times 10^{7} \mathrm{UFC} / \mathrm{g}$ & $5,0 \times 10^{7} \mathrm{UFC} / \mathrm{g}$ & $1,5 \times 10^{8} \mathrm{UFC} / \mathrm{g}$ \\
\hline 2 & $1,5 \times 10^{8} \mathrm{UFC} / \mathrm{g}$ & $2,0 \times 10^{8} \mathrm{UFC} / \mathrm{g}$ & $2,0 \times 10^{8} \mathrm{UFC} / \mathrm{g}$ \\
\hline 4 & $1,3 \times 10^{9} \mathrm{UFC} / \mathrm{g}$ & $5,5 \times 10^{8} \mathrm{UFC} / \mathrm{g}$ & $2,3 \times 10^{9} \mathrm{UFC} / \mathrm{g}$ \\
\hline 6 & $1,3 \times 10^{9} \mathrm{UFC} / \mathrm{g}$ & $3,5 \times 10^{8} \mathrm{UFC} / \mathrm{g}$ & $7,0 \times 10^{9} \mathrm{UFC} / \mathrm{g}$ \\
\hline 8 & $1,2 \times 10^{9} \mathrm{UFC} / \mathrm{g}$ & $3,5 \times 10^{8} \mathrm{UFC} / \mathrm{g}$ & $1,7 \times 10^{9} \mathrm{UFC} / \mathrm{g}$ \\
\hline 10 & $7,0 \times 10^{8} \mathrm{UFC} / \mathrm{g}$ & $8,5 \times 10^{8} \mathrm{UFC} / \mathrm{g}$ & $9,6 \times 10^{9} \mathrm{UFC} / \mathrm{g}$ \\
\hline 12 & $7,0 \times 10^{8} \mathrm{UFC} / \mathrm{g}$ & $1,5 \times 10^{8} \mathrm{UFC} / \mathrm{g}$ & $8,0 \times 10^{9} \mathrm{UFC} / \mathrm{g}$ \\
\hline
\end{tabular}

UFC: Unidade formadora de colônia.

tados podem ter sido influenciados pela concentração de inulina nas formulações. Rao ${ }^{29}$, estudando o efeito da ingestão de baixo nível de oligofrutose em humanos por três semanas, concluiu que $5 \mathrm{~g} /$ dia de oligofrutose estimula seletivamente o crescimento de bifidobactérias; Freitas et al. ${ }^{27}$, estudando o efeito prebiótico de frutooligossacarídeos em suco misto, observaram que o aumento na contagem de bifibobactérias ocorreu no grupo alimentado com dieta contendo 4,5\% de frutooligossacarídeos.

Fuchs et al. ${ }^{30}$ constaram que a suplementação do iogurte de soja deve ser feita adicionandose $14,24 \%$ de oligofrutose, $4,43 \%$ de inulina e tempo de fermentação de 6 horas e consideraram que a bebida é uma boa opção para o consumo de derivados de soja e substâncias prebióticas. Hauly et al. ${ }^{21}$, avaliando a mesma bebida, concluíram que os microrganismos probióticos (Lactobacillus bulgaricus e Streptococcus thermophilus) mantiveram a viabilidade celular necessária para caracterizar o iogurte como prebiótico e que os frutooligossacarídeos (oligofrutose e inulina) mostram-se adequados como ingredientes para formulação de iogurte de soja, devido ao bom índice de aceitação.

Convém ressaltar que, a utilização das porcentagens $0,5 \%$ e 1,0\% de inulina foi baseada na recomendação de Reid et al. ${ }^{22}$, que sugerem doses de 1-3g por dia de ingestão de prebióticos para crianças e a quantidade empregada nos produtos industrializados disponíveis no mercado. Assim sendo a concentração de $0,5 \%$ de inulina (formulação B) forneceria $1 \mathrm{~g} /$ dia e a formulação com $1,0 \%$ de inulina (formulação C) forneceria 2g/dia desse composto.

Porém, considerando que a contagem bacteriana das formulações foi de $10^{8}$ a $10^{9}$ unidade formadora de colônia (UFC)/mL e a legislação em vigor, que determina que todos os microrganismos produtores de fermentação láctea devem ser viáveis e estar presentes no produto em quantidades mínimas de $10^{6} \mathrm{UFC} / \mathrm{mL}^{26,28}$, sugerem-se estudos complementares para avaliar o efeito prebiótico da bebida. Vale salientar, o trabalho realizado por Wiele et al. ${ }^{31}$, que estudaram o efeito prebiótico da inulina e concluíram que sua ação é dependente do período de suplementação e que, para manter o efeito prebiótico e o crescimento das bactérias benéficas, o uso da inulina deveria ser contínuo.

Quanto às análises de AGCC, foi obtida a baixa produção de ácido acético $\left(C_{2}\right)$ presente em apenas algumas amostras das formulações $B(10 h)$ e da formulação C (2 e 4h), o que poderia ser explicado por Cummings ${ }^{32}$, que ressalta que a utilização de frutanos por Lactobacillus, Escherichia coli e Clostridium perfringens não é significativa, e, ainda, que as bactérias homofermentativas produzem, em média, 90\% de lactato e pequenas quantidades de acetato, etanol, dióxido de carbono ou acetona ${ }^{22,23}$.

\section{O N CLUSÃO}

Os resultados obtidos nas condições da presente pesquisa, permitem concluir que as bebidas são nutricionalmente adequadas para pequenas refeições (lanches) de crianças de 4 a 6 anos e bem aceitas pelo público-alvo, podendo seu uso ser sugerido para programas sociais como, o Programa Nacional de Alimentação Escolar. O aumento das bactérias homofermentativas indica que as formulações apresentam efeitos prebióticos 
in vitro, mas que se fazem necessários estudos complementares para testar os efeitos prebióticos in vivo.

\section{A GRADECIMENTOS}

Ao Laboratório de Experimentação e Análises de Alimentos - Nonete Barbosa Guerra/UFPE; à Prefeitura da Cidade do Recife (Creche Municipal Roda de Fogo), à Creche Beneficente Sant'Ana e ao Conselho Nacional de Desenvolvimento Científico e Tecnológico.

\section{COLABORADORES}

K.C. SILVEIRA foi responsável pela dissertação e pelas análises físico-químicas, microbiológicas, estatística e sensorial. J.A. BRASIL colaborou nas análises físico-químicas. A.V.S. LIVERA colaborou na análise dos dados estatísticos. S.M. SALGADO colaborou na etapa da fermentação. Z.P. FARO colaborou no desenvolvimento da bebida. N.B. GUERRA colaborou na análise sensorial e na redação final.

\section{REFERÊ N CIAS}

1. Silva RML. Estudo sobre a inocuidade das hortaliças de maior comercialização na CEAGEPE a partir da avaliação da utilização emprego de pesticidas na produção [dissertação] Recife: Universidade Federal de Pernambuco; 1996.

2. Seo JS, Burri BJ, Iquan Z, Neidlinger TR. Extraction and chromatography of carotenoids from pumpkin. J Chromatogr A. 2005; 1073(1-2): 371-5.

3. Faro ZP. Aproveitamento industrial da polpa de abóbora [tese]. Recife: Universidade Federal de Pernambuco; 2001.

4. Thamer LG, Penna ALB. Caracterização de bebidas lácteas funcionais fermentadas por probióticos e acrescidas de prebiótico. Ciênc Tecnol Aliment. 2006; 26(3):589-95.

5. International Vitamin A Consultative Group. Conversion factors for vitamin A and Carotenoids. Washington (DC): ILSI Research Foundation; 2002.

6. Ambrósio CLB, Campos FACS, Faro ZP. Aceitabilidade de flocos desidratados de abóbora. Rev Nutr. 2005; 19(1):39-45.
7. Brasil. Ministério da Saúde. Agência Nacional de Vigilância Sanitária. Resolução, RDC n. 12, de 2 de janeiro de 2001. Aprova o regulamento técnico sobre padrões microbiológicos para alimentos. Diário Oficial da União 2001. [acesso em 2006 jan 23]. Disponível em: <http://e-legis.bvs.br/leisref/ public/showAct. . php?id=144>

8. Association of Official Analytical Chemistry. Official methods of analysis of official analytical chemist internacional. 18th ed. Washington (DC); 2002.

9. Association of Official Analytical Chemistry. Official methods of analysis of official analytical chemist internacional. 2004. [cited 2006 Feb 20]. Available from: <http://eoma.aoac.org/methods/info.asp? ID $=5707>$.

10. Rodriguez-Amaya DB. A guide to carotenoid analysis in foods. Washington (DC): International Life Sciences Institute Press; 1999.

11. Dietary Reference intakes for vitamin A. vitamin $K$, arsenic, boron, chromium, copper, iodine, iron, manganese, molybdenum, nickel, silicon, vanadium, and zinc. Washington (DC): National Academy of Sciences; 2001.

12. Dutcosky SD.Análise sensorial de alimentos. Curitiba: Champagnat; 1996.

13. Barry JL, Hoebler C, MacFarlane GT, MacFarlane S, Mathers JC, Reed KA, et al. Estimation of fermentability of dietary fiber in vitro: a European Interlaboratory study. Br J Nutr. 1995; 74(3):303-22.

14. Cambrodon IG, Martin-Carron N. Fermentación colónica de fibra dietética y almidón resistente. In: Lajolo FM, Saura-calixto F, Penna EW, Menezes EW. Fibra dietética em Iberoamérica: tecnologia y salud. São Paulo: Varela; 2001.

15. Vanderzant C, Splittsloesser DF. Compendium of methods for the microbiological examination of foods 4th ed. Washington (DC): American Public Health Association; 2001.

16. Salgado SM, Livera AVS, Guerra NB, Schüller ARP, Araújo ALL. Resposta fisiológica do feijão macassar (vigna unguiculata $L$ walp). Braz J Food Techenol. 2006; 9(4):297-303.

17. Franco BDGM, Landgraf M. Microbiologia dos alimentos. São Paulo: Atheneu; 2004.

18. Bosscher D, Caillie-Bertrad MV, Cauwenbergh RV. Availabilities of calcium, iron and zinc from dairy infant formulas is affected by soluble dietary fibers and modified starch fractions. Nutrition. 2003; 19(7-8):641-5.

19. Greger JL. Nodigestible carbohydrates and mineral bioavailability. J Nutr. 1999; 129:1434s-5s. 
20. Brasil. Agência Nacional de Vigilância Sanitária. Referências para cálculo de valor diário para crianças. [acesso em 2006 jan 23]. Disponível em: <http://www.anvisa.gov.br/alimentos/rotulos/ crianca.htm>.

21. Hauly MCO, Fuchs RHB, Prudêncio-Ferreira SH. Suplementação de iogurte de soja com frutoligosacarídeos: características probióticas e aceitabilidade. Rev Nutr. 2005; 18(5):613-22.

22. Reid G, Beuerman D, Heinemann C, Bruce AW. Probiotic lactobacillus dose required to restore and maintain a normal vaginal flora. FEMS Immunol Med Microbiol. 2001; 32(1):37-41.

23. Rycroft CE, Jones MR, Gibson GR, Rastall RA. A Comparative in vitro evaluation of the fermentation properties of prebiotic oligosaccharides. J Appl Microbiol. 2001; 91(5):878-87.

24. Boone DR, Castenholz RW, Garrity GM. Bergey's manual of systematic bacteriology. New York: Springer; 2001.

25. Schlegel HG. General microbiology 7th. ed Cambridge: Cambridge University Press; c1993.

26. Thamer LG, Penna ALB. Efeito do teor de soro, açúcar e oligossacarídeos sobre a população de bactérias probióticas em bebidas fermentadas. Rev Bras Ciênc Farmacêuticas. 2005; 41(3):393-400.
27. Freitas DGC, Jackix MNH. Efeito da bebida adicionada de frutoligosacarídeo e pectina no nível de colesterol e estimulação de bifibobactérias em hamsteres hiper colesterolêmicos. Braz J Food Technol. 2005; 8(1):81-6.

28. Brasil. Ministério da Agricultura e Abastecimento. Regulamento técnico de identidade e qualidade de bebidas lácteas. Diário Oficial da União. 2005 24 ago; seção l; p.7.

29. Rao VA. The prebiotic propertie of oligofructose at low intake levels. Nutr Res. 2001; 21(6):843-8.

30. Fuchs RHB, Bosato D, Bona E, Hauly MCO. logurte de soja suplementado com oligofrutose e inulina. Ciênc Tecnol Aliment. 2005; 25(1):175-81.

31. Wiele TV, Boon N, Possemier S, Jacob H, Verstraete W. Prebiotics effects of chicory inulin in the simulator of the human intestinal microbial ecosystem. FEMS Microbiol Ecol. 2004; 51(1): 143-53.

32. Cummings JH, MacFarlane GT, Englyst HN. Prebiotic digestion and fermentation. AM J Clin Nutr. 2001; 73(2):415s-20s.

Recebido em: 7/5/2007

Versão final reapresentada em: 30/10/2007 Aprovado em: 29/2/2008 